Article

\title{
Diversified Farms Facing the Covid-19 Pandemic: First Signals from Italian Case Studies
}

\author{
Luigi Mastronardi ${ }^{1}\left(\mathbb{D}\right.$, Aurora Cavallo $^{2, *} \mathbb{\infty}$ and Luca Romagnoli ${ }^{1}$ \\ 1 Department of Economics, University of Molise, 86100 Campobasso, Italy; \\ luigi.mastronardi@unimol.it (L.M.); luca.romagnoli@unimol.it (L.R.) \\ 2 Faculty of Economics, Universitas Mercatorum, 00186 Rome, Italy \\ * Correspondence: a.cavallo@unimercatorum.it
}

Received: 10 June 2020; Accepted: 13 July 2020; Published: 16 July 2020

\begin{abstract}
The paper focuses on the effects of the Covid-19 pandemic on some Italian farms. In particular, the aim is to investigate the consequences of the health emergency on diversified farms, their reactions, and their agricultural and rural policy needs in order to overcome the crisis. The research path investigates five farms of central Italy through semi-structured interviews. The identified case studies are characterized by the heterogeneity of features and farms' activities. These activities include agritourism, on-farm processing of plant and animal products (mainly olive oils, fruits, and cheese), bio-energy production, tastings and leisure activities, educational farms, and contracting of farm equipment. A qualitative-quantitative analysis based on textual analysis techniques, particularly content and sentiment analysis, was performed. The results highlight the importance of farm diversification and networks in farms' strategies in dealing with the Covid-19 crisis. Furthermore, the presence of both synergies and trade-offs in different types of diversification is found. These results have interesting policy implications that should be more explicitly taken into account to target the next rural development measures.
\end{abstract}

Keywords: Covid-19 emergency; diversified farms; textual analysis techniques; Italy

\section{Introduction}

The paper deals with the first qualitative and quantitative evaluation of the consequences of the Covid-19 emergency on a small sample of Italian diversified farms.

In September 2019, the Global Preparedness Monitoring Board (GPMB), an independent monitoring and advocacy body chaired by Gro Harlem Brundtland, publishes its first report [1], urging political action to mitigate the effects of global health emergencies.

Pandemic episodes have always been part of the human experience, but in the last years, a combination of global trends, including climate change and urbanization, has sped up their reappearance. Figure 1 summarizes the main influences and pandemics of the last two centuries from a chronological point of view. As can be seen, in the first twenty years of the twenty-first century, the incidence is clearly increasing. Population growth and the resulting strains on the environment, climate change, urbanization, and exponential increases in international travel increase the risk everywhere.

The GPMB reviewed recommendations from previous high-level panels and commissions following the 2009 H1N1 flu pandemic and the 2014-2016 Ebola outbreak, along with its own commissioned reports and other data. The result is a snapshot that, with impressive precision, summarizes the outcomes of the difficulties of countries and international organizations in preventing and containing a global health threat. 
The Covid-19 pandemic caused substantial shocks for agriculture and food systems worldwide. The destruction of production capacity, changes in consumer preferences and their purchasing patterns, and fractures in value chains are just some of the effects of the pandemic [1]. Furthermore, a systemic uncertainty ensued socially and economically. Indeed, the agri-food sector has been one of the least affected by the economic storm of these months, largely confirming its anti-cyclical characteristics.

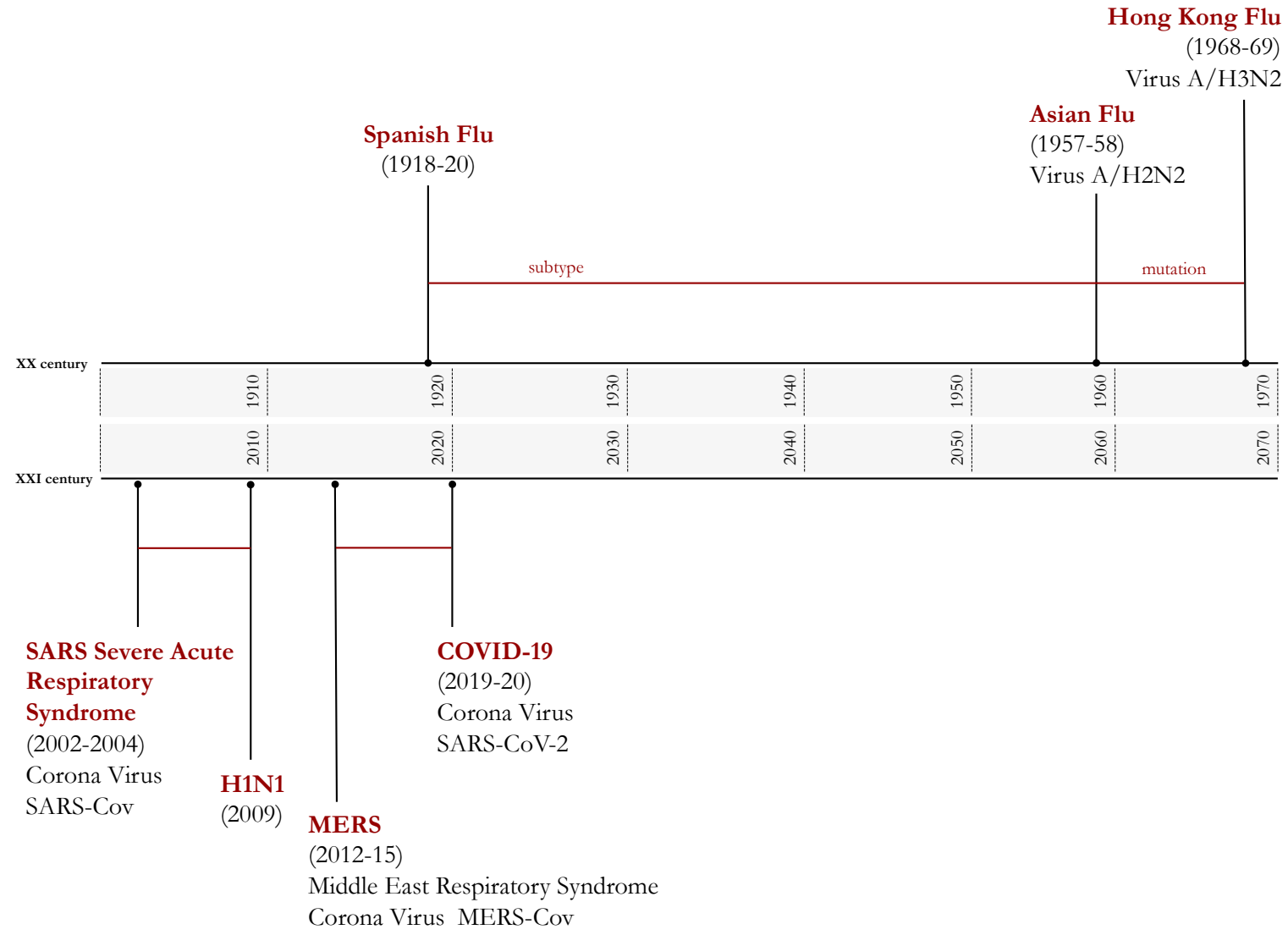

Figure 1. Main pandemics in 20th and 21st centuries. Source: Authors' own elaboration.

In the early stages of the pandemic, during the lockdown, there was a drastic reduction in demand and supply capacity generated by the rules of physical distancing of people, by traffic bans, and by the mandatory closure of economic activities, as well as by individual and collective reactions to the risk of contagion. In the period following the quarantine phase, changes related to business strategies, consumption preferences induced by income erosion, and learning processes from current experiences can be identified.

The difficulties for the agri-food system are emphasized by the drop in international trade, which, in the Italian case, is aggravated by the blockade of the Hotels-Restaurants-Catering (Ho.Re.Ca.) channel, one of the main drivers of Italian exports in the sector. Even on the domestic market, the most evident negative factors are connected to the travel bans, absence of tourist flows, the closure of the local markets as well as mall and shopping centers, and the difficulties affecting the availability of labor and logistics, which had serious repercussions on the agri-food system as a whole, leading to a profound change in consumption.

Despite the adoption of measures aimed at reducing the virus's effects, the presence of contagion risk in dairies, fruit and vegetable processing centers, slaughterhouses, and meat processing centers, as well as at transport companies, led to the breakdown of the supply chain, affecting the access to agricultural raw material as well as the delivery of products, with higher production costs or lower working capacity $[2,3]$. 
During the quarantine, the interest shown by consumers in local markets and the attention paid to food purchases had important effects on the food supply chain. For this reason, this paper focuses on the analysis of farms included in the local supply circuits. Furthermore, since the impacts of the pandemic were particularly severe during the quarantine, this paper is addressed to analyze the effects on farms during the lockdown.

The starting point of the study is that farms with activities related to agricultural production have shown greater resilience to the crisis.

In this framework, the aim of the paper is to investigate the effects of the health emergency on diversified farms, their reactions, and their agricultural and rural policy needs for overcoming the crisis due to Covid-19. A small sample of diversified farms has been chosen because the starting hypothesis is that farms with related activities may have had a greater adaptation to the crisis and more effective risk management.

Farm diversification represents the development of income-earning activities outside the range of conventional crop and livestock enterprises associated with agriculture [4-7]. It involves a diversion of production factors, such as land or labor, or capital, which were previously committed to conventional agricultural activities. Among the types of related activities, agritourism, on-farm processing of plant and animal products, bio-energy production, tastings and leisure activities, contracting of farm equipment, and care farming can be identified.

Diversification is also a key issue in agricultural and rural policy of several countries, and specifically in European Union (EU) in the debate surrounding the Common Agricultural Policy (CAP) reform, as well as in the EU Horizon 2020 strategies.

According to some authors [8], the farm income basis can be diversified by broadening, deepening, and regrounding. The broadening includes the development activities connected to agricultural and rural resources, such as rural tourism and landscape management; deepening refers to the vertical integration of food processing in the supply chains; finally, regrounding refers to the mobilization of farms' resources as new forms of cost reduction for off-farm income.

Several studies have investigated the role of diversification of farm income as a survival strategy in fragile areas [9-12], or how a greater integration with the local context makes these farms less vulnerable [13-17]. These features, in turn, promote a better positioning in the agri-food chain, retaining a greater share of added value in the farm through the transformation of agricultural products, improving technical and financial performance [18-22], and making farms able to face changes and faster in doing so.

The research path investigates five diversified farms of central Italy through semi-structured interviews. The identified case studies are characterized by the heterogeneity of features and farm activities. We applied a qualitative-quantitative analysis based on textual analysis techniques. The results highlight the importance of farm diversification and networks in farms strategies. This paper contributes to the literature by providing an analysis of farm household decisions while explicitly taking into account the effects of the Covid-19 pandemic. Furthermore, this study has interesting policy implications for the future agricultural and rural policies for targeting farm support at the EU level, as well as at the national and regional scales.

The paper is structured as follows: Section 2 illustrates the data collection steps and the methodologies employed, which include text and sentiment analysis; Section 3 presents the results of the analyses and discusses them; Section 4 concludes the study with some final remarks.

\section{Data Set and Methods}

The data were collected by means of direct interviews administered to the holders of the interested farms using an electronic platform in the period of 12-15 May 2020, during the lockdown arising from the Covid-19 pandemic. There were five farms, localized between two Middle Adriatic Italian regions, Abruzzo (comprising the provinces of Teramo, L'Aquila, Pescara, and Chieti) and Molise (including the provinces of Campobasso and Isernia). Figure 2 shows the study area. 


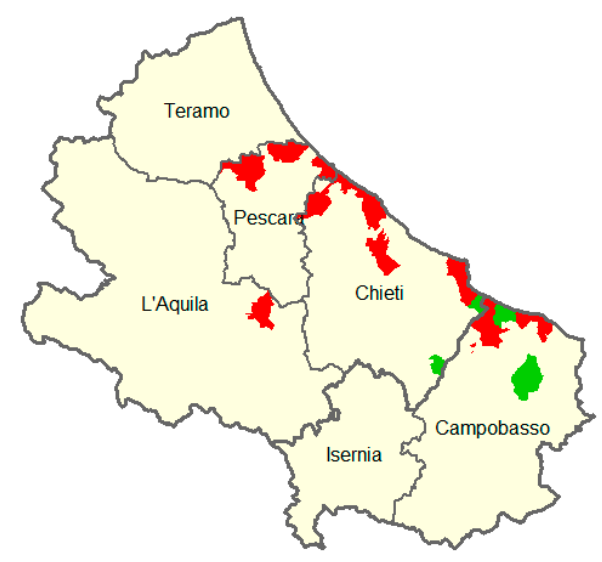

Figure 2. The provinces of Abruzzo and Molise. The municipalities in which sample farms are located are indicated in green; in red, the municipalities most affected by Covid-19. Source: Authors' own elaboration.

As stated in Section 1, all of the farms-denoted only by a number-are diversified. They were involved in the study for three reasons: (a) They are already part of a scientific project named DEMETRA, with the goal of promoting the integration between animal and plant production in marginal Central and Southern Italian areas; (b) diversified activities make them more dynamic in the market with respect to traditional farms [23], so it is more interesting to investigate the effects of Covid-19 on their business; (c) all of them have trade relations with enterprises and consumers located in several municipalities that were greatly affected by the virus.

Table 1 presents the main features of the farms and their related activities.

A semi-structured questionnaire was administered, leaving responses open for the most part. The themes addressed can be synthesized in three key questions:

1. What are the main effects deriving from the Covid-19 pandemic on farms?

2. What kinds of interventions have been made in response to the effects of Covid-19?

3. What are the forms of support that you request to cope with the consequences of this emergency?

The interviews were registered and then transcribed for subsequent analysis. A pilot interview allowed us to solve some issues that were present in the first version of the questionnaire.

Two techniques were applied to the answers: Text analysis and sentiment analysis. They are methods that make it possible to get as much information as possible from a small number of interviews. They were chosen because the statistical units were very few, so the application of any purely quantitative technique would be infeasible.

Standard text analysis preparation steps were followed [24], particularly text import (the operation of reading texts from our Word format files), string operations, and preprocessing (the techniques for manipulating raw texts and processing them into tokens-i.e., units of text, such as words or word stems), to get to the document-term matrix (DTM), that is, the matrix of all processed terms (tokens) with the corresponding frequencies.

The next step was the application of sentiment analysis methods. Sentiment analysis (or opinion mining) is the computational study of people's opinions, sentiments, evaluations, and emotions. It has been a very active research area in natural language processing, data mining, and web mining for years; recently, its applications have also been extended to management and social sciences [25]. The method employed was the so-called "lexicon-based" one, which uses semantic strength to define the sentiment of both single terms and entire answers. It exploits dictionaries, the construction of which can be automatic or manual [26]. In this study, an ad hoc dictionary was implemented, giving a sentiment to each of the words pronounced by the respondents. Two experts in agricultural economics read the answers and gave their evaluations to the words, with a value ranging from -4 (strong negative sentiments) to +4 (strong positive sentiment). Giving a score to the terms was rather simple in the 
present case, since each word could refer only to a precise concept-the effects of the pandemic, the interventions in response to crisis, or the requested support. Comparing this situation to other kinds of text, where multiple objects might be discussed in a context that is difficult to assess, makes it clear how it was easy to estimate the real meaning of each expression in this application.

Table 1. (a) Main features and (b) related activities of farms.

\begin{tabular}{|c|c|c|c|c|c|}
\hline (a) Main Features & Farm 1 & Farm 2 & Farm 3 & Farm 4 & Farm 5 \\
\hline Farm leadership & Manager & Owner & Owner & Manager & Owner \\
\hline Legal form & Ltd company & Individual company & Individual company & Ltd company & Individual company \\
\hline Farm size & $>50$ ha & $25-50$ ha & $25-50$ ha & $>50$ ha & $>50$ ha \\
\hline Farm manager's age & $<40 \mathrm{y}$ & $<40 \mathrm{y}$ & $>40 y$ & $<40 \mathrm{y}$ & $>40 y$ \\
\hline Labor force & Employees & Family workers & Family workers & Employees & Family workers \\
\hline Profitable & Yes & Yes & Yes & Yes & Yes \\
\hline (b) Related activities & Farm 1 & Farm 2 & Farm 3 & Farm 4 & Farm 5 \\
\hline Agritourism & - & - & & & \\
\hline Dairy & - & & & & \\
\hline Educational farm & - & - & & & \\
\hline Farm shop & - & - & - & - & - \\
\hline Livestock processing & & & & & - \\
\hline Olive oil production & - & & & & \\
\hline $\begin{array}{l}\text { Vegetable processing } \\
\text { Windmill }\end{array}$ & & $\bullet$ & - & $\bullet$ & $\bullet$ \\
\hline
\end{tabular}

The mean of the two expert judgments was considered first. A second dictionary was then used, containing intensifiers (e.g., 'very', 'much', 'many', and others) and diminishers (e.g., 'slightly', 'pretty', 'a bit', and so on), that is, terms that change the degree of the final semantic orientation. The final intensity was calculated by multiplying the original sentiment by the diminisher (a value less than 1 ) or the intensifier (a value greater than 1).

The final output consists of three word clouds, one for each theme, containing the words with the highest or lowest sentiment, calculated on all five respondents' answers. They highlight the keywords that, together with an analysis of the literature on the topic, allow us to make some points on the influence of the pandemic on the selected farms.

All of the analyses were carried out by means of the R software.

\section{Results and Discussion}

In Table 2, a summary of the results of the procedure described in the previous section is presented. For each of the interviewees, absolute (Abs) and relative (Rel) semantic orientations are shown; in particular, the first measure is the sum of the sentiments attributed to each word of the answer, while the second is simply the ratio between absolute orientation and the total number of words.

Table 2. Summary of the results of sentiment analysis.

\begin{tabular}{ccccccc}
\hline & Abs 1 & Abs 2 & Abs 3 & Rel 1 & Rel 2 & Rel 3 \\
\hline Farm 1 & -73.00 & -8.00 & 56.75 & -0.21 & -1.00 & 0.31 \\
Farm 2 & -85.25 & 28.50 & 137.50 & -0.41 & 0.09 & 0.35 \\
Farm 3 & 405.50 & 5.00 & 146.75 & 1.24 & 0.28 & 0.53 \\
Farm 4 & 8.00 & 5.00 & 110.00 & 0.03 & 0.33 & 0.60 \\
Farm 5 & 83.25 & 4.00 & 71.25 & 0.15 & 0.57 & 0.31 \\
Total & 338.50 & 34.50 & 522.25 & 0.19 & 0.10 & 0.41 \\
\hline
\end{tabular}

The first comment concerns the sign of the semantic orientations: It is possible to see that only three answers have a negative sentiment, two of which relate to the first question about the effects of the crisis. Maybe this result, which was obtained by Respondents 1 and 2, is due to the presence of agritourism and educational farms, the activities they had to stop during the lockdown. The second issue reported an overall low positive semantic orientation, and this is probably due to the fact that 
all of the farmers are waiting to verify the results of their interventions. The third theme scored only positive sentiments; the support requested is deemed necessary for competing in markets and facing eventual new health emergencies.

Some more words are needed for the highest sentiment. In particular, an extremely high absolute value was recorded for Farm 3 for Issue 1. This may be due, on one hand, to the absence of activities that were stopped during the lockdown (present in Farms 1 and 2) or, on the other hand, to the lack of activities that slowed down (like the windmill in Farm 4 or livestock processing in Farm 5). The fact that this farm diversifies its activities mainly in direct selling proved to be a strength with respect to the others.

Our final observation regards relative sentiments. They express the average positivity or negativity in the answer, providing a better understanding of the respondents' attitude. The issue reporting the highest positivity is the third (Total sentiment/Total words $=0.41$ ); among the farms, the fourth registered the highest relative value, probably indicating a greater need for aid.

Figure 3 shows the results of sentiment analysis results concerning the main impacts deriving from the Covid-19 pandemic on farms. The font dimension reflects sentiment intensity, while the color shows the direction, which can be negative (red) or positive (green). Negative sentiment indicates farms' criticalities, while positive orientation denotes the opportunities that appeared during the emergency. The difference between total positive and total negative sentiment is positive, meaning that the overall assessment is oriented to evaluate the effects of the crisis on business in a favorable manner.

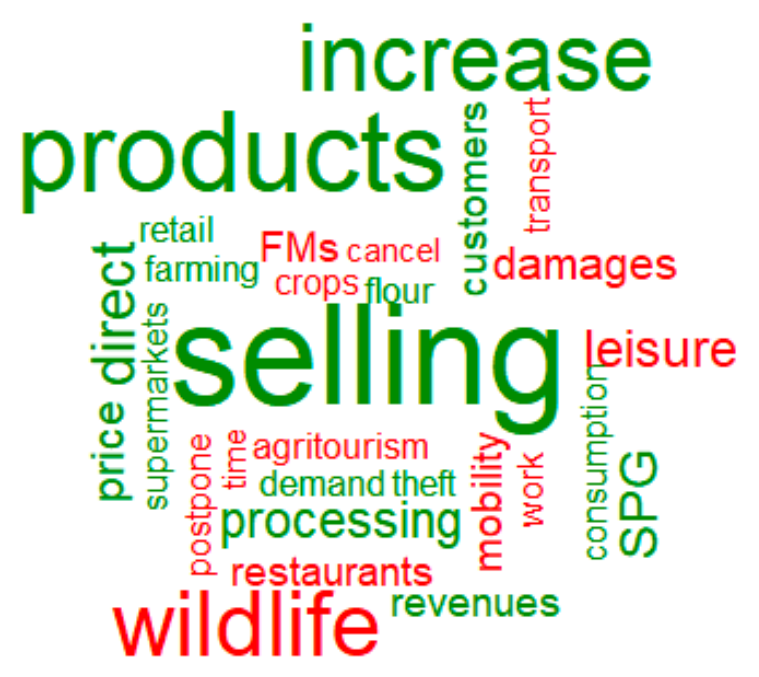

Figure 3. Main effects deriving from the Covid-19 pandemic on farms. Source: Authors' own elaboration.

All of the respondents declared that they experienced no particular effects on their core farming business, while there were significant effects on the distribution of products and on the so-called related activities, such as agritourism, leisure, and restaurants.

A very strong positive sentiment was expressed towards the increase in sales, particularly of transformed products-e.g., flour-but even of fresh products. Both the quantities sold to former customers and the number of new customers increased, owing to the great amount of time spent at home by families, who also used this time to prepare any kind of homemade food, such as bread, pasta, and pizza. In this regard, it is worth noting that containment measures prohibited the consumption of meals outside the house. In this sense, the Covid-19 emergency has changed eating habits. Furthermore, the farmers interviewed have not increased their prices, in contrast with large supermarket chains, and this has led to a further demand growth. The lockdown resulted in augmented direct sales, particularly to Solidarity Purchasing Groups (SPGs) and, to a lesser extent, to supermarkets located inside cities. Consequently, revenues from direct selling have increased, thus ensuring the liquidity needed to carry on the business. In the last decades, the functioning and the structure of agri-food 
markets have gradually changed [27]. Covid-19 has sped up this change and has strengthened the sales in Short Food Supply Chains (SFSCs). These chains, in turn, reinforce sustainability [28] and can give a positive contribution to a healthier and fairer future in food consumption [29]. In brief, SFSCs might facilitate the transition towards sustainable local agri-food systems that are capable of granting access to quality food to all [30].

Among the negative effects of the pandemic, the respondents reported the increase of wildlife in the countryside, particularly boars, due to the greatly reduced mobility across the nation. Wildlife could damage crops and, therefore, involve new costs in protecting the cultivations or a reduction in future revenues because of a contraction in harvest. Other negative consequences concerned the cancellation of reservations, with repercussions on agritourism activities, especially restaurants and leisure. Agritourism is an important factor of rural development [31], particularly from the environmental [32], social, and economic [33] viewpoints; a sharp contraction of these activities could result in negative effects on local economies. The closure of Farmers' Markets (FMs) prevented the farmers from selling their vegetable products in these markets. The revenues from agritourism business and from sales to FMs have decreased. There has been a small deficiency in work force, which has led to postponement in time of some farming operations.

In spite of these difficulties, the effects coming from the pandemic are positive overall, since total revenues have increased and the expectations of the respondents are optimistic, also as to related activities. It is hoped that they will restart normally, despite the reduced number of guests enforced by social distancing.

Figure 4 depicts the results concerning the farmers' responses to the changes determined by the health crisis. The most important reaction concerned the sales methods. The goods were delivered to the homes of SPG customers, while before, they were delivered to a single distribution center; containment measures have prevented the gathering of people in common spaces. These deliveries took place using their own means of transportation because the delivery charges applied by couriers have increased greatly, as have transport times. This new method has been greatly appreciated by customers, who have avoided the long and boring queues, which have been registered outside any store. On the other hand, farmers have suffered due to the additional time and work requirements. As a result, some farming operations have been deferred in time. Some SPG customers have chosen to pick up their goods directly in the shop; in this case, the orders and the deliveries have been managed through Whatsapp. Online sales have significantly risen. The share of sales, which has been lost due to closing of FMs, has been replaced by an equal amount sold to non-profit organizations, such as episcopal curia, at discounted prices. This type of sale has played an important role, especially with processed products (flour, oil, pasta, and others) because it has allowed the sale of excess goods stored in the warehouse.

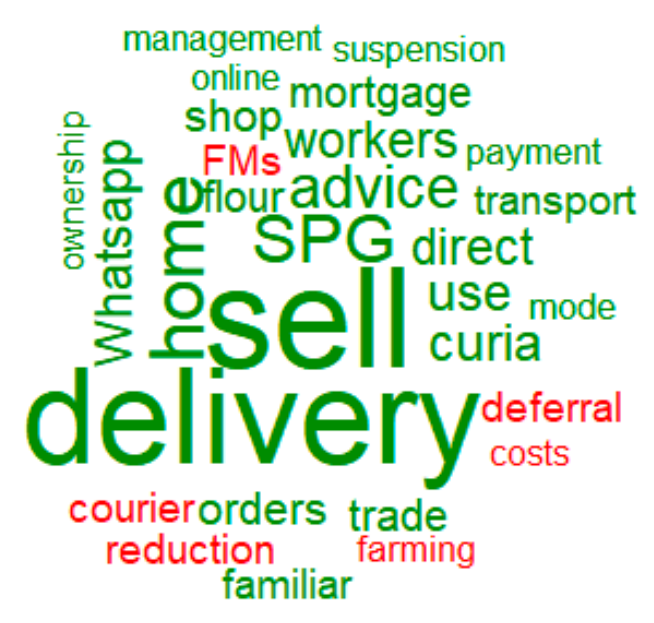

Figure 4. Farmers' responses to the Covid-19 crisis. Source: Authors' own elaboration. 
The increase in the activities, together with the impossibility of using the manpower usually coming from different municipalities, especially those declared as "red zones", has led to a lack of labor force. This has been overcome through the recourse to familiar work and to the reorganization of the operations. Several households' members working in the industry have lost their jobs, so they could devote all of their energy to the farms' activities. Some advisory activities have been carried out in online mode by exploiting photos and videos of the crops and communicating with consultants through electronic platforms and software. Some of the respondents had contracted mortgages, relying on the possibility of repaying them through agritourism's revenues. These farmers have chosen to suspend them because of the sudden lack of this source of income.

The final question concerned the farmers' needs in dealing with the Covid-19 crisis, and the results are reported in Figure 5.

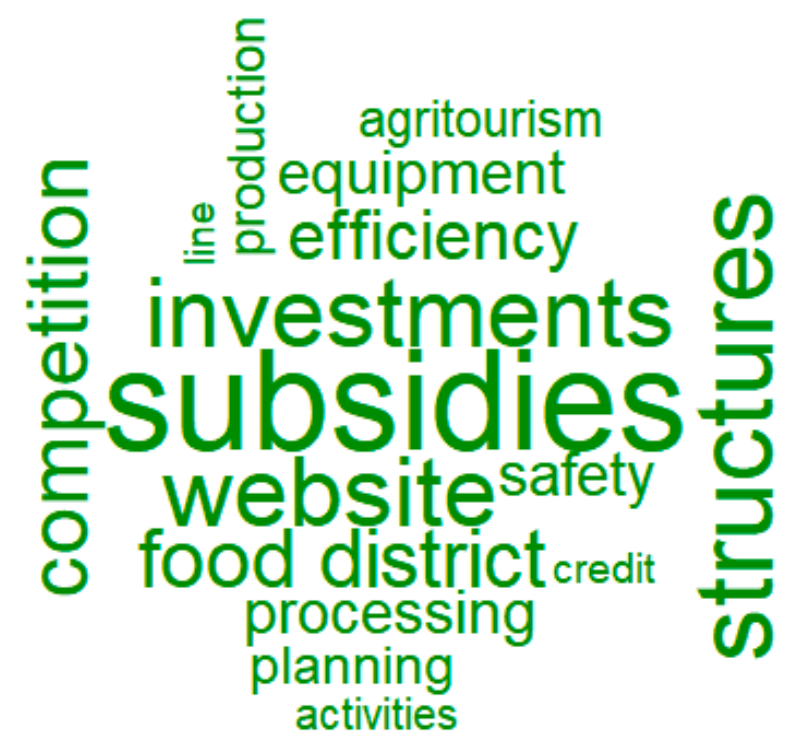

Figure 5. Farmers' needs in dealing with the Covid-19 crisis. Source: Authors' own elaboration.

The major requests are represented by subsidies and, to a lesser degree, credit lines with the purpose of making new investments, which are necessary to improve the efficiency of production structures. In turn, the latter allows farms to gain competitiveness in the markets. One of the main ideas is to implement or strengthen a website, which could ensure additional direct sales. Another potential investment concerns the enhancement of processing activities, especially for olive, wheat, vegetable, and milk treatment. This point is of particular importance, since the processing operations have been outsourced to different enterprises in the last decades [34], and farmers now wish to re-appropriate these business activities. Subsidies could also serve to upgrade and renovate equipment, and to adjust agritourism structures to the new post-Covid standards. Moreover, in order to improve farms' competitiveness, the respondents are determined to set up a 'Food district': This is a new tool that was established by Italian Law 205/2017, and represents an instrument to promote local development within a place-based approach through the integration of activities characterized by territorial proximity.

\section{Conclusions}

The Covid-19 pandemic has had particularly significant impacts on the agri-food system. The food supply chain is a complex network of interactions and actors: Producers, inputs, transport, processing plants, shipping, and more. During the quarantine, the food supply chains were disrupted with blockages to transport routes that were particularly obstructive for fresh food and a labor-intensive crop crisis due to the limited availability of manpower, which also resulted in increased levels of food loss and waste. However, the Covid-19 pandemic stressed the importance of a solid and resilient food 
system that functions in all circumstances and is capable of ensuring citizens a sufficient supply of affordable food [35].

On the consumer side, the food demand is inelastic, and the effect of the pandemic on overall food consumption likely limited. Furthermore, at the beginning of the diffusion of the disease, significant increase in demand for fresh food and home-prepared food transformed traditional consumption styles. The pandemic also helped make consumers more aware of the interrelationships between health, ecosystems, supply chains, consumption patterns, and sustainability [35].

This paper investigated the effects of the pandemic on farms that diversify in some areas of Central Italy. The interviews conducted showed how the pandemic highlighted the centrality of agricultural activity and food production, as well as their origins, also in terms of food safety and quality. Moreover, farmers that were interviewed registered a sharp contraction in agricultural production activities throughout the quarantine, but also a sharp increase in sales of food products. In particular, the SFSCs and local marketing channels have not only shown themselves to be more resilient, but have had an important boost. From this point of view, Covid-19, at least in the short term, has caused a transformation of the food supply chain in favor of local markets and short supply chain channels.

The networking and aggregation among farms are other key issues. If, to date, the national tools and policies aimed at promoting synergies among farms have substantially failed, the quarantine could have catalyzed a mechanism of necessity and, therefore, of trust that could also consolidate in the coming months. This theme could have territorial cohesion effects, which are also favored on the other front, as the interviews have shown through the strengthening of the links between farmers and consumers. Indeed, the survey that was conducted revealed how the closure of some commercial channels (i.e., FMs and direct sales on farm) has forced farms to strengthen others, such as the SPGs and the direct delivery. Again, the new adaptation strategies for both consumers and farmers-not only in the event of a new upsurge in Covid-19 in the autumn, but also as a response to the current economic crisis-could lead to a strengthening cooperation among all actors in the food supply chain.

On the supply side, one of the most relevant elements is the re-orientation of the farms. In fact, both as an effect of new consumer requests and as a risk adaptation strategy, farms require subsidies and for policymakers to invest in modernization of food processing machinery and logistics. This factor could represent an indirect impact of the pandemic, determining a farm's leaning towards greater technical efficiency and competitiveness as a strategy of resilience and adaptation to the crisis, as highlighted by the word clouds.

Furthermore, in some interviews, farmers referred to the start of cooperation with volunteering and third-sector organizations. These collaborations could further consolidate in the coming months. In general, the crisis caused by the pandemic seems to have favored the spread of innovation on a local scale. In this sense, the word clouds have highlighted new forms of social innovations: Farm networking and cooperation between producers and consumers, as well as between farms and non-profit organizations.

In addition, the word clouds show technological innovation in food processing. Therefore, in their local food networks, the farms seem to have responded to the difficulties of the pandemic crisis by showing a remarkable adaptability. These features are fundamental in farms that diversify, which are characterized by flexibility and resilience to transformations and risks.

In the interviews, it emerged that, due to the transformations induced by the pandemic, farmers also tried to adapt through the search for new management skills, as well as problem-solving and learning-by-doing approaches. These skills show the central role of human capital formation in agriculture, which has a significant implication for policymakers.

This paper sought to contribute to the launch of a theoretical debate between scholars and international experts aimed at assessing the impacts of the pandemic and the resilience of farms, businesses, and communities to risk.

The results of this investigation point out that the impacts of the pandemic had effects on both deepening and regrounding. This evidence highlights an important implication for the post-Covid-19 
agricultural and rural policy design. In fact, in the CAP reform process that is underway, the reduction in funding of the Second Pillar represents an element of risk, far removed from the needs of the farms shown in the pandemic.

In April 2020, the European Commission published "A Farm to Fork Strategy", in which it promotes a global approach to the role of food sustainability and urges national, regional, and local institutions to build a broad debate on a sustainable food policy. Furthermore, the Commission has undertaken to formulate a legislative proposal for a sustainable food system by the end of 2023 .

This study has connected different policy implications. First, the research highlights the centrality of food production among farm activities, so it is important that rural policies assign a key role to the support of agriculture. In addition, ties emerge with the territory, communities, citizens-consumers, and other farms. This is a second priority element for the design of upcoming policies; support for food supply chains must be built through a place-based approach, looking at their local dimensions.

Local markets, farmers' markets, and direct sales need to be supported as factors for increasing value and favoring the distribution of bargaining power in the agri-food supply chains towards farms, thus protecting consumers. In addition, it is important to concentrate subsidies in the direction of increasing farm competition and investments in agro-food processing machinery.

A limitation to be pointed out is that the study suffers from the limitedness of the number of interviews and of the geographic area covered. The scope of the research, in any case, is to offer timely signals of the effects of Covid-19 on diversified farms in this first post-quarantine phase; a survey based on a representative sample from the whole Italian farm population would have required much more time.

Future research efforts should be addressed in some directions. Firstly, we should compare the results with interviews conducted in ultra-peripheral areas to investigate the effects of Covid-19 in the inner and mountain regions. Secondly, a research guideline that we believe may be interesting is that related to understanding the effects of the pandemic and quarantine on social cohesion in rural areas, an element that emerged during the interviews and that deserves further research efforts.

Author Contributions: Conceptualization, A.C., L.M., and L.R.; methodology, L.R.; software, L.R.; formal analysis, L.M. and L.R.; investigation, L.M.; writing-original draft preparation, A.C., L.M., and L.R.; writing-review and editing, A.C., L.M., and L.R. All authors have read and agreed to the published version of the manuscript.

Funding: Luigi Mastronardi and Luca Romagnoli were supported by the DEMETRA project, funded by the Italian Ministero delle Politiche Agricole, Alimentari e Forestali (D.M. no 77662 dated 07/11/2019).

Conflicts of Interest: The authors declare no conflict of interest.

\section{References}

1. Global Preparedness Monitoring Board Secretariat. A World at Risk; Report No. 1; World Health Organization: Geneve, Switzerland, 2020.

2. ISMEA. Emergenza COVID-19. In I Rapporto Sulla Domanda e L'Offerta dei Prodotti Alimentari Nelle Prime Settimane di Diffusione del Virus; ISMEA: Rome, Italy, 2020.

3. ISMEA. Emergenza COVID-19. In II Rapporto Sulla Domanda e L'Offerta dei Prodotti Alimentari Nelle Prime Settimane di Diffusione del Virus; ISMEA: Rome, Italy, 2020.

4. Fuller, A.M. From Part-Time Farming to Pluriactivity: A Decade of Change in Rural Europe. J. Rural Stud. 1990, 6, 361-373. [CrossRef]

5. Ilbery, B. Farm diversification as an adjustment strategy on the urban fringe of the West Midlands. J. Rural Stud. 1991, 7, 207-218. [CrossRef]

6. McInerney, J.; Turner, M.; Hollingham, M. Diversification in the Use of Farm Resources; Report No. 232; Department of Agricultural Economics, University of Exeter: Exeter, UK, 1989.

7. De Roest, K.; Ferrari, P.; Knickel, K. Specialisation and economies of scale or diversification and economies of scope? Assessing di_erent agricultural development pathways. J. Rural Stud. 2018, 59, 222-231. [CrossRef] 
8. Van der Ploeg, J.D.; Roep, D. Multifunctionality and Rural Development: The Actual Situation in Europe. Multifunctional Agriculture: A New Paradigm for European Agriculture and Rural Development; Ashgate Publishing Company: Aldershot, UK, 2003; pp. 37-54.

9. Meert, H.; Van Huylenbroeck, G.; Vernimmen, T.; Bourgeois, M.; van Hecke, E. Farm household survival strategies and diversification on marginal farms. J. Rural Stud. 2005, 21, 81-97. [CrossRef]

10. Bowler, I.; Clark, G.; Crockett, A.; Ilbery, B.; Shaw, A. The development of alternative farm enterprises: A study of family labour farms in the northern Pennines of England. J. Rural Stud. 1996, 12, 285-295. [CrossRef]

11. Vik, J.; McElwee, G. Diversification and the Entrepreneurial Motivations of Farmers in Norway. J. Small Bus. Manag. 2011, 49, 390-410. [CrossRef]

12. Castellano-Álvarez, F.J.; del Río-Rama, M.D.L.C.; Álvarez-García, J.; Durán-Sánchez, A. Limitations of Rural Tourism as an Economic Diversification and Regional Development Instrument. The Case Study of the Region of La Vera. Sustainability 2019, 11, 3309. [CrossRef]

13. Darnhofer, I. Strategies of family farms to strengthen their resilience. Environ. Policy Gov. 2010, $20,212-222$. [CrossRef]

14. Katchova, A.L. The Farm Diversification Discount. Am. J. Agric. Econ. 2005, 87, 984-994. [CrossRef]

15. Barbieri, C.; Mahoney, E. Why is diversification an attractive farm adjustment strategy? Insights from Texas farmers and ranchers. J. Rural Stud. 2009, 25, 58-66. [CrossRef]

16. Boncinelli, F.; Bartolini, F.; Casini, L.; Brunori, G. On farm non-agricultural activities: Geographical determinants of diversification and intensification strategy. Lett. Spat. Resour. Sci. 2016, 10, 7-29. [CrossRef]

17. Ciolac, R.; Adamov, T.; Iancu, T.; Popescu, G.; Lile, R.; Rujescu, C.; Marin, D. Agritourism: A Sustainable Development Factor for Improving the "Healt" of Rural Settlements. Case Study Apuseni Mountains. Sustainability 2019, 11, 1467. [CrossRef]

18. McElwee, G.; Bosworth, G. Exploring the Strategic Skills of Farmers across a Typology of Farm Diversification Approaches. J. Farm Manag. 2010, 13, 819-838.

19. Dries, L.; Pascucci, S.; Gardebroek, C. Diversification in Italian farm systems: Are farmers using interlinked strategies? New Medit 2012, 4, 7-15.

20. Barnes, A.P.; Hansson, H.; Manevska-Tasevska, G.; Shrestha, S.S.; Thomson, S.G. The influence of diversification on long-term viability of the agricultural sector. Land Use Policy 2015, 49, 404-412. [CrossRef]

21. Morris, W.; Henley, A.; Dowell, D. Farm diversification, entrepreneurship and technology adoption: Analysis of upland farmers in Wales. J. Rural Stud. 2017, 53, 132-143. [CrossRef]

22. Salvioni, C.; Henke, R.; Vanni, F. The Impact of Non-Agricultural Diversification on Financial Performance: Evidence from Family Farms in Italy. Sustainability 2020, 12, 486. [CrossRef]

23. ISTAT. Rapporto Annuale 2019. La Situazione del Paese; ISTAT: Rome, Italy, 2019.

24. Welbers, K.; Van Atteveldt, W.; Benoit, K. Text Analysis in R. Commun. Methods Meas. 2017, 11, $245-256$. [CrossRef]

25. Liu, B. Many facets of Sentiment Analysis. In A Practical Guide to Sentiment Analysis; Cambria, E., Das, D., Bandyopadhyay, S., Feraco, A., Eds.; Springer International Publishing AG: Cham, Switzerland, 2017; pp. 11-39. [CrossRef]

26. Taboada, M.; Brooke, J.; Tofoloski, M.; Voll, K.; Stede, M. Lexicon-Based Methods for Sentiment Analysis. Comput. Linguist. 2011, 37, 267-307. [CrossRef]

27. Borsellino, V.; Schimmenti, E.; El Bilali, H. Agri-Food Markets towards Sustainable Patterns. Sustainability 2020, 12, 2193. [CrossRef]

28. Mastronardi, L.; Marino, D.; Cavallo, A.; Giannelli, A. Exploring the Role of Farmers in Short Food Supply Chains: The Case of Italy. Int. Food Agribus. Manag. Rev. 2015, 18, 109-130.

29. Craveiro, D.; Marques, S.; Marreiros, A.; Bell, R.; Khan, M.; Godinho, C.; Quiroga, S.; Suárez, C. Equity, health, and sustainability with prove: The evaluation of a portuguese program for a short distance supply chain of fruits and vegetables. Int. J. Environ. Res. Public Health 2019, 16, 5083. [CrossRef] [PubMed]

30. Mastronardi, L.; Romagnoli, L.; Mazzocchi, G.; Giaccio, V.; Marino, D. Understanding consumer's motivations and behaviour in alternative food networks. Br. Food J. 2019, 121, 2102-2115. [CrossRef]

31. Sgroi, F; Donia, E.; Mineo, A.M. Agritourism and local development: A methodology for assessing the role of public contributions in the creation of competitive advantage. Land Use Policy 2018, 77, 676-682. [CrossRef] 
32. Lupi, C.; Giaccio, V.; Mastronardi, L.; Giannelli, A.; Scardera, A. Exploring the features of agritourism and its contribution to rural development in Italy. Land Use Policy 2017, 64, 383-390. [CrossRef]

33. Giaccio, V.; Giannelli, A.; Mastronardi, L. Explaining determinants of Agri-tourism income: Evidence from Italy. Tour. Rev. 2018, 73, 216-229. [CrossRef]

34. Marino, D. (Ed.) Agricoltura Urbana e Filiere Corte: Un Quadro Della Realtà Italiana; FrancoAngeli: Milano, Italy, 2016.

35. European Commission. A Farm to Fork Strategy for a Fair, Healthy and Environmentally-Friendly Food System. In Communication from the Commission to the European Parliament, the Council, the European Economic and Social Committee and the Committee of the Regions; COM (2020) 381 final; European Commission: Brussels, Belgium, 2020.

(C) 2020 by the authors. Licensee MDPI, Basel, Switzerland. This article is an open access article distributed under the terms and conditions of the Creative Commons Attribution (CC BY) license (http://creativecommons.org/licenses/by/4.0/). 